\title{
Arbuscular mycorrhizal fungi reduce the differences in competitiveness between dominant and subordinate plant species
}

\author{
Pierre Mariotte • Claire Meugnier • David Johnson • \\ Aurélie Thébault • Thomas Spiegelberger • \\ Alexandre Buttler
}

Received: 18 June 2012 / Accepted: 2 October 2012 / Published online: 14 October 2012

(C) Springer-Verlag Berlin Heidelberg 2012

\begin{abstract}
In grassland communities, plants can be classified as dominants or subordinates according to their relative abundances, but the factors controlling such distributions remain unclear. Here, we test whether the presence of the arbuscular mycorrhizal (AM) fungus Glomus intraradices affects the competitiveness of two dominant (Taraxacum officinale and Agrostis capillaris) and two subordinate
\end{abstract}

P. Mariotte $(\bowtie) \cdot$ C. Meugnier $\cdot$ A. Thébault $\cdot$ T. Spiegelberger

A. Buttler

School of Architecture, Civil and Environmental Engineering

(ENAC), Laboratory of Ecological Systems (ECOS),

Ecole Polytechnique Fédérale de Lausanne (EPFL),

Station 2,

1015 Lausanne, Switzerland

e-mail: pierre.mariotte@epfl.ch

P. Mariotte $\cdot$ A. Thébault $\cdot$ A. Buttler

Swiss Federal Institute for Forest,

Snow and Landscape Research (WSL),

Site Lausanne, Station 2,

1015 Lausanne, Switzerland

\section{Johnson}

Institute of Biological and Environmental Sciences,

University of Aberdeen,

Cruickshank Building, St Machar Drive,

Aberdeen AB24 3UU, UK

T. Spiegelberger

Irstea, Research Unit Mountain Ecosystems (UR EMGR),

2 rue de la Papeterie, Saint-Martin-d'Hères, BP 76,

38402 Grenoble, France

\section{A. Buttler}

Laboratoire de Chrono-Environnement,

UMR CNRS 6249, UFR des Sciences et Techniques,

Université de Franche-Comté,

16 route de Gray,

25030 Besançon, France species (Prunella vulgaris and Achillea millefolium). Plants were grown in pots in the presence or absence of the fungus, in monoculture and in mixtures of both species groups with two and four species. In the absence of $G$. intraradices, dominants were clearly more competitive than subordinates. In inoculated pots, the fungus acted towards the parasitic end of the mutualism-parasitism continuum and had an overall negative effect on the growth of the plant species. However, the negative effects of the AM fungus were more pronounced on dominant species reducing the differences in competitiveness between dominant and subordinate species. The effects of $G$. intraradices varied with species composition highlighting the importance of plant community to mediate the effects of AM fungi. Dominant species were negatively affected from the AM fungus in mixtures, while subordinates grew identically with and without the fungus. Therefore, our findings predict that the plant dominance hierarchy may flatten out when dominant species are more reduced than subordinate species in an unfavourable AM fungal relationship (parasitism).

Keywords Competitive effects - Glomus intraradices . Grasslands · Mutualism-parasitism · Plant diversity · Plant hierarchy $\cdot$ Subordinate species

\section{Introduction}

Semi-natural grasslands are widespread components of northtemperate landscapes and have important roles in providing grazing for livestock and acting as reservoirs of both carbon (Follett and Reed 2010) and biodiversity (Cremene et al. 2005; Baur et al. 2006). In particular, grasslands developing on calcareous substrates tend to contain a large diversity of 
plants including several rare, threatened and iconic species. For example, in the Swiss Jura wood pastures, plant communities result from a traditional management with regular grazing and trampling disturbance and have a long succession history with well-established vegetation communities where up to 40 species may inhabit $1 \mathrm{~m}^{2}$ (Gigon and Leutert 1996; Buttler et al. 2009). Given their crucial and contrasting ecosystem services, it is important that species-rich grasslands are conserved. This aim requires understanding of the processes that govern the composition and stability of species-rich plant communities.

Observations of plant species abundances in semi-natural grasslands reveal distinct frequency distributions, with some species found frequently and in high abundance (dominants), and some also found frequently but in low abundance (subordinates; Grime et al. 1987; Olff and Bakker 1998). Some species may also be considered transients because they rarely persist (Whittaker 1965). Dominant species are generally few in number, tall and account for a large proportion of the total community biomass. In contrast, subordinate species consistently co-occur with particular dominants, are often small in stature and contribute marginally to the total biomass of the community, although they are the most diverse component of communities. The role of dominant species in ecosystem functioning has received considerable research attention and, according to the "mass ratio" theory (Grime 1998), ecosystem properties are determined by dominant species independent of changes in species richness that involve variations in the number of subordinate species. However, more recent studies show that less abundant species may have a larger influence on ecosystem properties and functioning than their relative abundance suggests (Lyons et al. 2005; Boeken and Shachak 2006). Thus, it becomes important to consider the factors that determine the abundance not only of dominants but also of subordinates.

In semi-natural, extensively managed grasslands, the roots of almost all plants are heavily colonised by arbuscular mycorrhizal (AM) fungi (Read et al. 1976). AM fungi often form large mycelial networks throughout soil and greatly facilitate acquisition and uptake of scarce or immobile mineral nutrients, particularly phosphorus (Johnson et al. 2001). In forming mycelial networks, individual mycorrhizal fungi can be supported by several host plants, and so the hyphae can facilitate seedling establishment (van der Heijden et al. 2004) and affect plant competition. Whilst the AM symbiosis is typically considered a mutualistic one, increasing evidence points to a more diverse range of interactions. In a meta-analysis, around $45 \%$ of studies found positive effects of AM fungi on plant growth, $30 \%$ showed no effect and $25 \%$ showed negative effects (van der Heijden and Horton 2009). This analysis supports the idea that AM fungi act along a continuum between mutualism and parasitism (Johnson et al. 1997; Klironomos 2003) and species competitiveness could be increased as well as decreased in the presence of AM fungi. Here, the net outcome of the symbiosis is likely dependent on the environment or may develop in different directions throughout the lifetime of a plant.

The contrasting functional characteristics of individual AM fungi therefore suggest that they may have important roles in shaping plant community composition and stability in grasslands. The effect of AM fungi on plant communities is also related to nutrient availability in soils, and it has been shown that low phosphorus status stimulates colonisation of roots by AM fungi, which feeds back to affect plant diversity and productivity (Collins and Foster 2009). AM fungi are completely dependent on host plants for carbon, and their biomass and activity means they are substantial sinks for plant assimilate (Johnson et al. 2002), which could therefore completely change the dominance hierarchy (Gross et al. 2010) following its degree of profit from particular plant species. Indeed, previous studies have demonstrated that subordinate and dominant plant species can show distinct responses to AM fungi (van der Heijden et al. 1998a; Yao et al. 2007; Karanika et al. 2008) which may influence plant dominance (Grime et al. 1987; van der Heijden et al. 1998b; Hartnett and Wilson 1999). Considering that AM fungi can act along a continuum between mutualism and parasitism (Johnson et al. 1997), there are two mechanisms which may explain the effects of AM fungi on plant dominance hierarchies: (1) dominant and subordinate species have different AM fungal dependency and species with higher dependency are favoured in competition in mutualistic interactions or (2) dominant and subordinate species show different responses to less favourable relationships with AM fungi, and one of these groups may be more affected by parasitism. For the first mechanism, these responses have been developed into a model whereby the relative response of dominants and subordinates to AM fungi determines plant community composition and dominance hierarchies (Urcelay and Diaz 2003). When mycorrhizal dependence of subordinates is strong, dominance rankings flatten out, so that overall plant species diversity increases. In contrast, when mycorrhizal dependence of dominants is strong and subordinates is weak, dominance rankings steepen in response to AM fungi, so that overall plant species diversity decreases. In the second mechanism, when dominant species are more affected than subordinate species in unfavourable relationships with AM fungi, dominance rankings may flatten out, and inversely, when subordinate species show higher biomass reduction than dominant species, dominance ranking steepens in the presence of AM fungi. To date, there have been few studies that explicitly test these hypotheses, with most of the evidence derived indirectly from experiments or observations related to the relative influence of mycorrhizal symbiosis on plant communities (Klironomos et al. 2011). 
Plant communities of wooded pastures in the Swiss Jura Mountains result from traditional cattle and forest management, and vegetation communities are well-established on unimproved soils with intermediate fertility. These grassland communities serve as an ideal model to explore the effect of AM fungi on plant interactions since they are very diverse and show a typical lognormal rank-abundance curve (Grime 1998) with a few dominant species accounting for a high proportion of the total community biomass. In this study, we chose four plant species which are native to species-rich calcareous grasslands. According to their relative abundance in the field, two of these species can be considered to be dominants and two as subordinates. Previous experiments in the field (unpublished) showed that these subordinate species were significantly more colonised by AM fungi (about $20 \%$ more) compared to dominants during seedling establishment. AM fungi could therefore be more beneficial to less competitive subordinates and explain their persistence in plant communities. In this paper, we report investigations of the competitive effect of two dominant and two subordinate species in different species composition when grown under control conditions and in the presence or absence of the ubiquitous AM fungus Glomus intraradices. We hypothesise that inoculation with $G$. intraradices will promote growth of subordinate plant species and reduce the differences in competitiveness with dominant species which will not or less draw benefit from the fungus.

\section{Materials and methods}

\section{Plant species selection}

Dominant and subordinate species were selected from measurements of community composition in semi-natural calcareous grasslands in the Swiss Jura Mountains (Les Amburnex, western Switzerland, 6 $13^{\prime} 50^{\prime \prime}$ E, 46 32'50" N). The field research site is an extensively grazed pasture with a vertic cambisol which contains intermediate value of carbonates

Table 1 Soil characteristics of the field soil (Les Amburnex) and the pot mixture used in the glasshouse experiment

\begin{tabular}{|c|c|c|}
\hline & Field site & Pot mixture \\
\hline $\begin{array}{l}\text { Available } \mathrm{P}\left(\mathrm{mg} \mathrm{kg}^{-1}\right) \\
\quad\left(\text { acetate } \mathrm{NH}_{4}^{+}+\text {EDTA } 1: 10\right)\end{array}$ & $4.47 \pm 0.15$ & $4.13 \pm 0.12$ \\
\hline Total P $(\%)$ & $0.18 \pm 0.03$ & $0.21 \pm 0.02$ \\
\hline $\begin{array}{l}\text { Available } \mathrm{Ca}\left(\mathrm{gkg}^{-1}\right) \\
\quad\left(\text { acetate } \mathrm{NH}_{4}^{+}+\text {EDTA } 1: 10\right)\end{array}$ & $11.27 \pm 0.29$ & $13.91 \pm 0.76$ \\
\hline Total organic $\mathrm{C}(\%)$ & $5.82 \pm 0.22$ & $4.09 \pm 0.19$ \\
\hline Total N (\%) & $0.67 \pm 0.06$ & $0.57 \pm 0.03$ \\
\hline $\mathrm{pH}\left(\mathrm{H}_{2} \mathrm{O}\right)$ & $6.81 \pm 0.06$ & $7.76 \pm 0.04$ \\
\hline
\end{tabular}

$\left(15 \% \mathrm{CaCO}_{3}\right)$ and relatively low level of available $\mathrm{P}$ (Table 1). Absolute plant cover was determined within 36 plots $(1.2 \times 1.2 \mathrm{~m})$ using a Braun-Blanquet index. A species was classified as dominant if its frequency was greater than $75 \%$ (100\% frequency means that the species is present in all plots) and its cumulative relative cover greater than $25 \%$. A species was classified as subordinate if its frequency was greater than $75 \%$ and its cumulative relative cover between 2 and $25 \%$ (adapted from Grime 1998). Based on their field abundance and results of their competitive abilities (effect and response) when growing together in a previous glasshouse experiment (Mariotte et al. 2012), we assigned Prunella vulgaris and Achillea millefolium as subordinate species and Agrostis capillaris and Taraxacum officinale as dominant species.

\section{Experimental design}

The pot experiment was set up as a randomised split-block design (Fig. 1) with two factors: (1) AM fungal inoculation treatment varying at the block level and (2) plant mixture type varying at the plot level. The inoculation treatment contained two levels: with $G$. intraradices inoculum (M treatment) and with non-mycorrhizal control inoculum (NM treatment). We chose the ubiquitous $G$. intraradices because it has a broad host range and is the most frequently detected phylotype in all grassland systems (Öpik et al. 2006) and the most abundant in Swiss meadows (Sýkorová et al. 2007). In this pot experiment, we used soil inoculum of G. intraradices Schenck \& Smith (isolate BEG 21), native from a calcareous grassland, which was provided by Prof. M.G.A. van der Heijden, Agroscope ART Zurich, Switzerland. G. intraradices was previously propagated from spores as a pure culture of Plantago lanceolata growing in autoclaved soil for 8 months in 2009 to provide recent highquality inoculum (further details about this inoculum in Veiga et al. 2012). The plant mixture type contained three levels: monocultures $(n=4)$, two-species mixtures including each combination of one dominant and one subordinate $(n=$ 4) and four-species mixture including two different dominants and two different subordinates $(n=1)$. All pots contained four individuals to maintain stable plant densities for each mixture type. The interaction of mixture type and AM inoculation treatment resulted in 18 combinations which were replicated six times, yielding a total of 108 pots arranged in six blocks.

Seeds germination, soil mixture and growing conditions

Seeds of the four species were gathered from the Swiss plateau (provided by FENACO SA, Yverdon-les-bains, Switzerland), stored at $4{ }^{\circ} \mathrm{C}$ prior to the start of the experiment, surface sterilised in $5 \%$ bleach for $10 \mathrm{~min}$ and then 
Fig. 1 Schematic diagram of the experimental design. Circles represent pots and contain plant combinations of dominant species: T. officinale $(D 1)$ and A. capillaris (D2), and subordinate species: $P$. vulgaris (S1) and A. millefolium (S2).

Each pot contained four individuals of the same species in monoculture (white), two individuals per species (one dominant and one subordinate) in two-species mixture (grey) and one individual per species (two dominants and two subordinates) in mixture of four species (dark grey). Combinations are reproduced either with $(M)$ or without (NM) AM fungal inoculation which varied at the plot level in six blocks

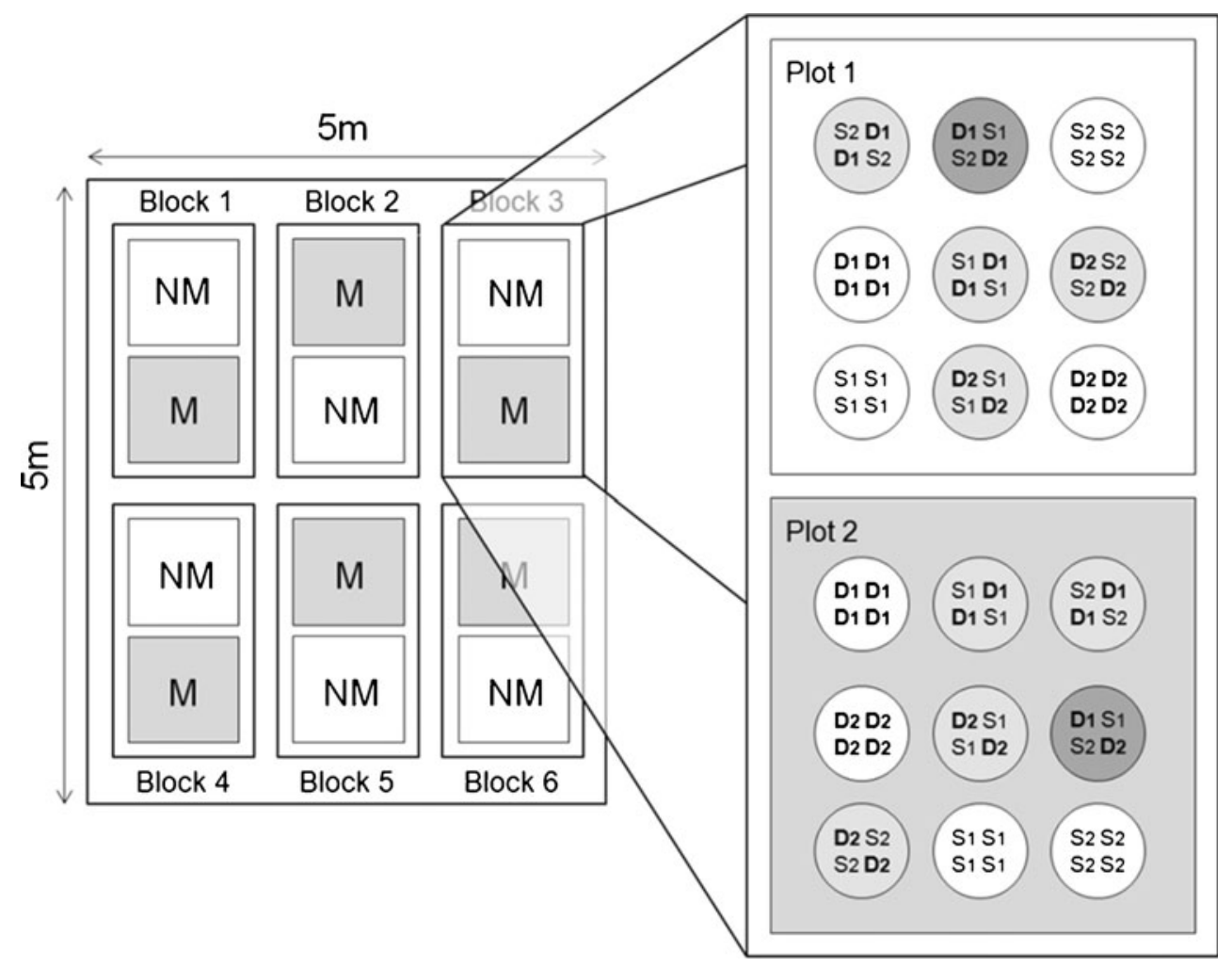

rinsed five times with distilled water. Around 700 seeds of each species were germinated on autoclaved water agar gel $(1.6 \%)$ in a phytotron over 6 days in the dark at $22^{\circ} \mathrm{C}$. One week later, seedlings were transplanted within an agar gel cube $\left(1 \mathrm{~cm}^{3}\right)$ and assembled following the different species mixtures into $1.5 \mathrm{~L}$ sterile plastic pots containing $800 \mathrm{ml}$ of a gamma sterilised sand (Berns et al. 2008) mixture (90\% sand and $10 \%$ compost) which recreated the low P availability measured in the field site (Table 1). Half of the pots received $40 \mathrm{ml}$ of $G$. intraradices inoculum added on the top soil ( $M$ treatment), while the control pots received $40 \mathrm{ml}$ of autoclaved inoculum (NM treatment). To compensate for the microbial community which may coexist with AM fungi in mycorrhizal pots, it is common practice to add an inoculum washing (filtered over $20 \mu \mathrm{m}$ ) to the non-mycorrhizal pots (e.g. Gavito et al. 2003; Van der Heijden et al. 2003; Chen et al. 2007). However, this does not necessarily include all microbes, and the microbial community added alone may have different effects on plant growth when added alone in the control pots (positive or negative due to changes in soil interactions) as to when coexisting with the AM fungus in mycorrhizal pots. For this reason, and as no effects of pathogens were detected in previous experiments using the same high-quality inoculum of $G$. intraradices BEG21 (Van der Heijden et al. 1998a, 2006; Wagg et al. 2011; Veiga et al. 2012), a microbial wash was not added to control pots. Nevertheless, the inoculum was checked for the absence of other microorganisms using two different approaches. Firstly, an inoculum washing (filtered over $20 \mu \mathrm{m}$ ) was put into culture (six replicates) in nutrient agar-agar (Sigma-Aldrich, St. Louis, MO, USA), and no significant development of bacteria or fungi was detected after 5 days. Secondly, P. lanceolata roots in the inoculum were stained with acid fuchsin (Gerdemann 1955) and scored for root colonisation on 50 intersections per root sample (10 replicates). Ninety percent of $P$. lanceolata root length was colonised by $G$. intraradices (see also Veiga et al. 2012), and fungal structures other than those belonging to AM fungi were not observed.

Pots were maintained in a glasshouse from April to July 2010 where day temperature varied between 25 and $38^{\circ} \mathrm{C}$, night temperature was $16^{\circ} \mathrm{C}$ and the day length was $15 \mathrm{~h}$. Because the glasshouse permitted $90 \%$ penetration of photosynthetically active radiation, additional light was not provided. During the first month, each pot was watered every day with the same volume of water $(200 \mathrm{ml})$ and then adjusted to maintain $10 \%$ water content. Plants received no fertilisation.

After 105 days, shoots were harvested for each species by cutting at ground level, and roots were collected by washing and sieving each individual. Root subsamples of selected individuals were used for determination of AM fungal colonisation. Shoot and root biomass were measured after drying in an oven at $60{ }^{\circ} \mathrm{C}$ for $72 \mathrm{~h}$. The average of the two (two-species mixture) or four (monoculture) individuals per species in each pot was calculated to obtain the overall root and shoot biomass per species per pot. As we did not 
observe any differences in root/shoot ratios following inoculation with $G$. intraradices, or by changing the mixtures of species, we focused on total plant biomass as the response variable in our analyses.

\section{Estimation of AM fungal colonisation}

The primary objective was to determine whether the inoculum had successfully colonised roots rather than to test for effects of mixture type and plant identity. Roots from each plant species in each community composition (four replicates) were stained with acid fuchsin as described by Gerdemann (1955). A minimum of 50 intersections per root sample were viewed microscopically and scored for the presence of vesicles, hyphae only and arbuscules. The absence of colonisation was also confirmed in uninoculated plants.

Relative effect of $G$. intraradices on plant growth

For each plant species grown in monoculture, as two-species mixtures or as four-species mixtures, the relative effect of $G$. intraradices was measured as:

$$
\text { AM fungal effect }{ }_{\mathrm{ij}}=\ln \left(\mathrm{Y}_{\mathrm{ij}} \mathrm{M} / \mathrm{Y}_{\mathrm{ij}} \mathrm{NM}\right)
$$

where $Y_{i j} M$ represents total plant biomass (root and shoot) of species $i$ growing with species $j$ in presence of the AM fungal inoculum and $\mathrm{Y}_{i j} \mathrm{NM}$ the biomass of the same species $i$ growing with species $j$ without the AM fungal inoculum. Positive values for AM fungal effect indicate a better growth in presence of $G$. intraradices (mutualism) and, inversely, negative values indicate a negative growth response to inoculation by $G$. intraradices (parasitism).

Competitiveness of dominant and subordinate plant species

The relative yield per plant (RYP) of each species was calculated from total biomass (root and shoot) in the mycorrhizal (M) and non-mycorrhizal (NM) treatments of twoand four-species mixtures, as:

$\mathrm{RYP}_{\mathrm{ij}}=\mathrm{Y}_{\mathrm{ij}} / \mathrm{Y}_{\mathrm{ii}}$

where $\mathrm{RYP}_{\mathrm{i}}$ is the relative yield per plant of species $i$ (i.e. target) grown with species $j$ (i.e. neighbour), $Y_{i j}$ is the yield of plant $i$ when grown with species $j$ and $Y_{i i}$ is the yield of plant $i$ when grown in monoculture (Engel and Weltzin 2008). When $\mathrm{RYP}_{i j}>\mathrm{RYP}_{j i}, j$ is less competitive than species $i$ and conversely, when $\mathrm{RYP}_{i j}<\mathrm{RYP}_{j i}, j$ is a better competitor than $i$.

Competitive effect (CE) of dominant species is defined as the mean RYP of $T$. officinale and $A$. capillaris grown with each subordinate species, and competitive effect of subordinate species is defined as the mean RYP of $P$. vulgaris and $A$. millefolium grown with each dominant species (Goldberg and Landa 1991). Species with a greater CE are better competitors, and inversely, species with a lower CE are less competitive. To test whether competitiveness changed when plants were colonised by $G$. intraradices, the CE of dominant and subordinate species was calculated for both mycorrhizal and nonmycorrhizal plants in two- and four-species mixtures.

\section{Statistical analysis}

Statistical analyses were undertaken in R version 2.11.1 (R Development Core Team 2010). Total plant biomass (after square root transforming), relative AM fungal effect and competitive effect were analysed using linear mixedeffects models with plot nested into block as random factors followed by Tukey's post hoc. For total plant biomass, datasets from each mixture type were analysed separately, and the analysis of relative AM fungal effect was also separated for each species.

\section{Results}

\section{Colonisation of roots by $G$. intraradices}

The root systems of the plant species inoculated with $G$. intraradices were heavily colonised, but AM fungal colonisation did not significantly differ between species. Colonisation of roots by vesicles (mean of $46 \%$ for $T$. officinale, $56 \%$ for $A$. capillaris, $80 \%$ for $P$. vulgaris and $63 \%$ for $A$. millefolium) and hyphae only (30\% for T. officinale, $33 \%$ for A. capillaris, $11 \%$ for P. vulgaris and $24 \%$ for $A$. millefolium) was high, but there was little development of arbuscules (less than $2 \%$ for each species). Plants not inoculated with $G$. intraradices remained uncolonised.

Plant productivity in experimental systems

Both subordinate and dominant plant species either produced less or equal biomass in the presence of $G$. intraradices compared to un-inoculated controls (Fig. 2). The effects of the AM fungus were very consistent among species when they were grown in monoculture (Fig. $2 \mathrm{a}$ ), reducing biomass by between 42 and $44 \%$ compared to the nonmycorrhizal controls. This resulted in an overall significant effect $\left(F_{1,5}=95.69, P<0.001\right)$ of the presence of $G$. intraradices and an overall significant effect of species $\left(F_{3,30}=\right.$ 12.32, $P<0.001)$ but no interaction $\left(F_{3,30}=0.29, P=0.82\right)$.

The patterns in plant biomass were broadly similar when plants were grown in two-species (Fig. 2b) or four-species (Fig. 2c) mixtures. In the two-species mixture, there was an overall significant interaction between addition of $G$. intraradices $\times$ plant species $\left(F_{3,78}=10.14, P<0.001\right)$. Both 
Fig. 2 Total plant biomass $( \pm 1 \mathrm{SE})$ of dominant $(T$. officinale and A. capillaris) and subordinate (P. vulgaris and $A$. millefolium) growing with (hatched bars) and without (white bars) G. intraradices in a monoculture, $\mathbf{b}$ two- and $\mathbf{c}$ four-species mixtures. Bars sharing a letter are not significantly different $(P>0.05)$

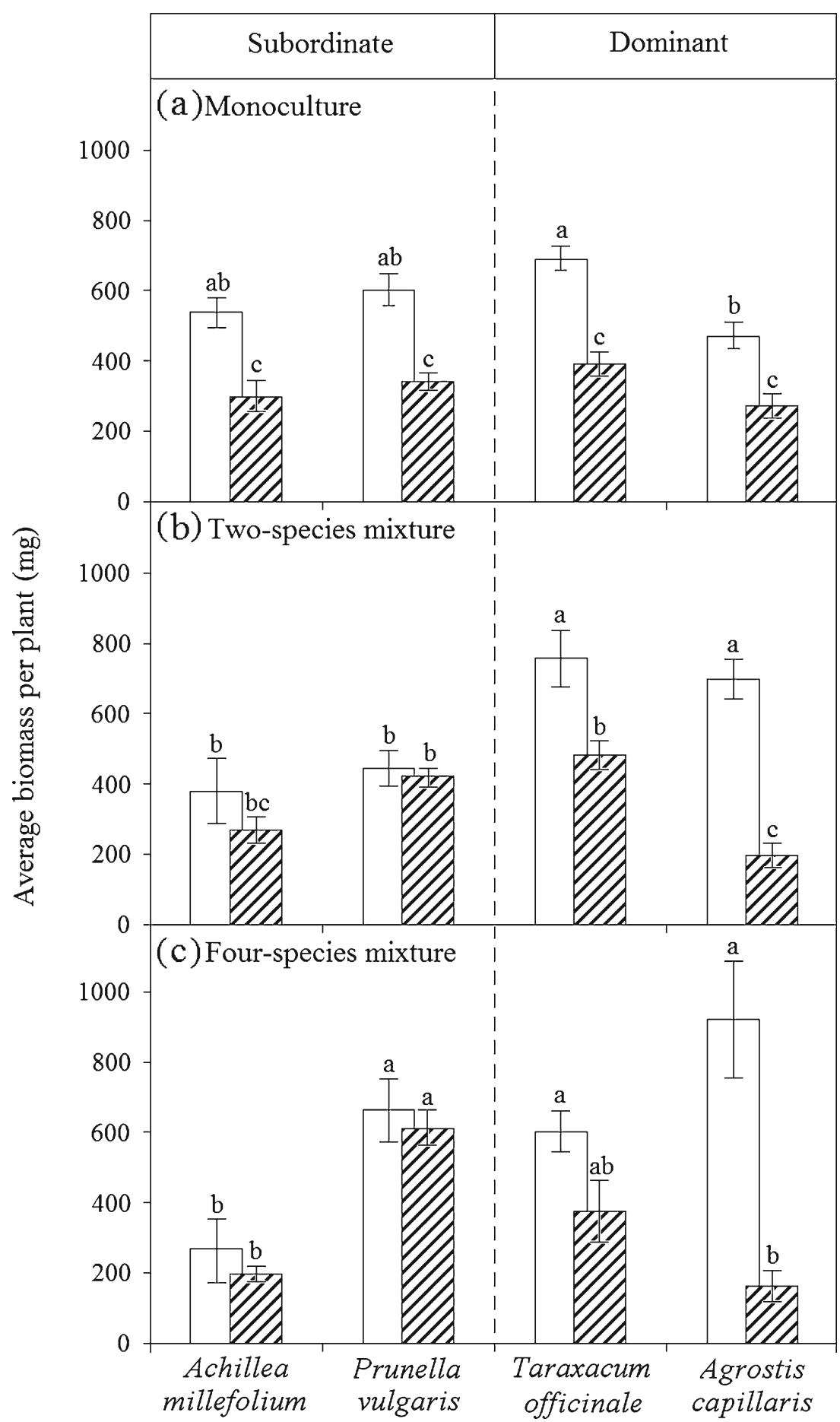

dominant species produced more biomass than subordinates in non-mycorrhizal plots, but these differences were removed in the presence of the fungus. Indeed, the biomass of $P$. vulgaris and A. millefolium was unaffected by $G$. intraradices, whereas the negative effects of the fungus were enhanced for $T$. officinale and A. capillaris.

When growing in a mix of four species (Fig. 2c), both subordinates $P$. vulgaris and $A$. millefolium produced similar biomass in the presence of $G$. intraradices compared to the controls (Fig. 2c). Dominant species produce less biomass in the presence of the fungus, and there was also a significant interaction between addition of $G$. intraradices $\times$ plant species $\left(F_{3,30}=8.79, P<0.001\right)$ mainly because of the poorer performance of $A$. capillaris in the four-species mixture.

The variation in biomass produced among species increased alongside species richness (Fig. 2a-c). For example, 
the biomass of non-mycorrhizal plants ranged from 540 to $693 \mathrm{mg}$ in monocultures, $313-756 \mathrm{mg}$ in two-species mixtures and 263-922 mg in the four-species mixtures. By comparison, the variation in biomass of mycorrhizal plants was less important as the species richness of the mixtures increased. These differences were also reflected by the magnitude of the overall negative effects of $G$. intraradices inoculation on the dominant $A$. capillaris and $T$. officinale when grown in mixtures. For example, in the four-species mixture, the biomass of $A$. capillaris was $82 \%$ less in the mycorrhizal condition compared to the non-mycorrhizal condition, while the biomass of $T$. officinale was $40 \%$ less.

AM fungal growth effect

The addition of $G$. intraradices had a similar negative effect on both dominant and subordinate species when they were grown in monoculture (Fig. 3), but the effects differed when the species were grown in mixtures. The relative AM fungal effect was always negative for the dominant species (T. officinale and A. capillaris) regardless of whether they were competing with their conspecifics or with one or two subordinates. The magnitude of the negative effect of $G$. intraradices on A. capillaris biomass increased in the four-species mixture compared to the two-species mixture. In contrast, the effect of $G$. intraradices remained constant across monocultures and mixtures for $T$. officinale. The patterns of relative AM fungal effect were the opposite for subordinate species. Here, the magnitude of negative effects tended to decrease in two- and four-species mixture. For example, $P$. vulgaris was unaffected by $G$. intraradices in mixtures of two and four species, whereas A. millefolium remained marginally affected in the two-species mixture but was unaffected in mixtures of four species.
Fig. 3 Relative AM fungal effect $( \pm 1 \mathrm{SE})$ of dominant $(T$. officinale and A. capillaris) and subordinate ( $P$. vulgaris and $A$. millefolium) species in monoculture (white), twospecies mixture (grey) and fourspecies mixture (dark grey). Bars sharing a letter are not significantly different $(P>0.05)$

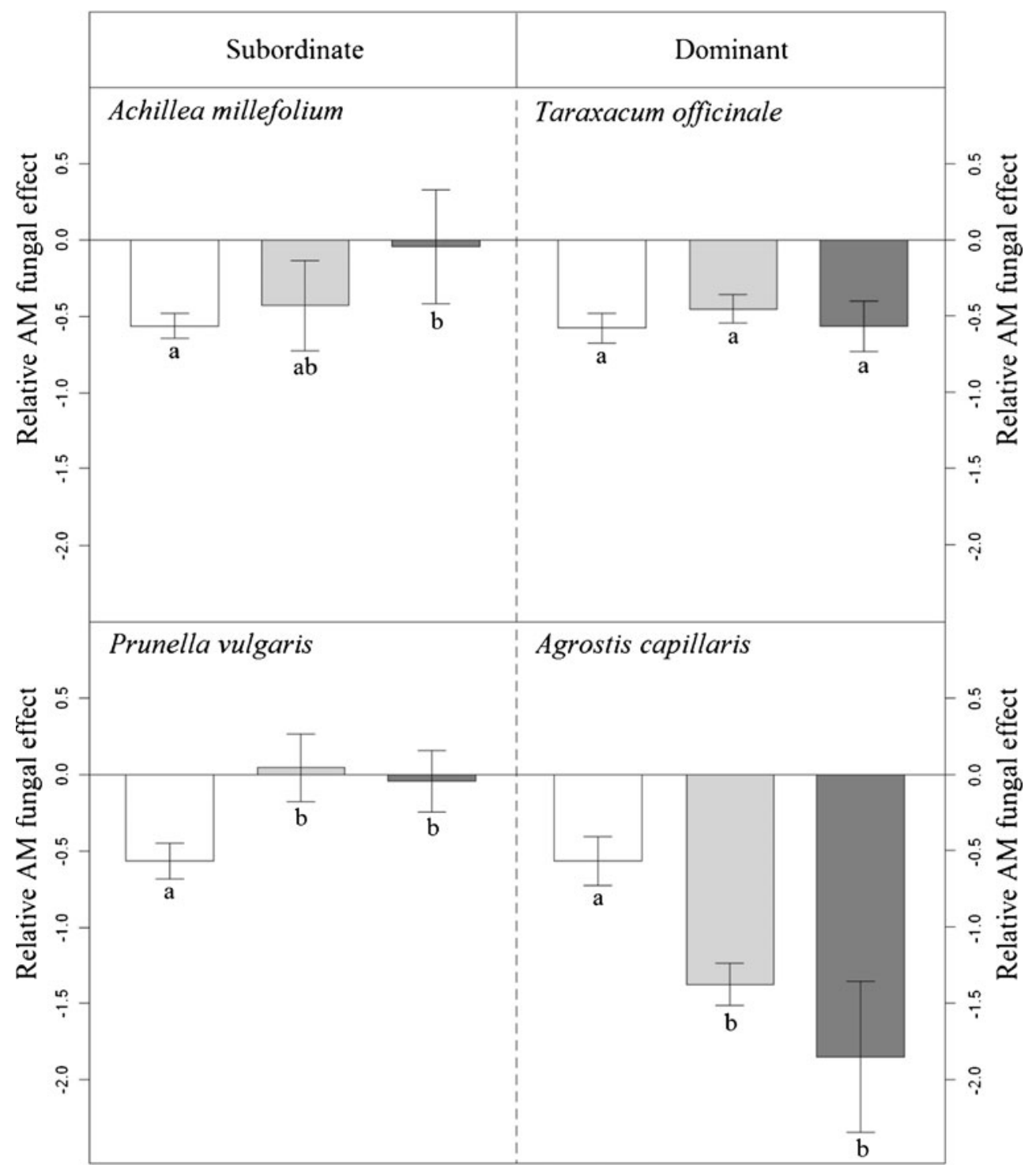




\section{Competitiveness of species groups}

In the absence of $G$. intraradices inoculation, the index of competitive effect was high for dominant species $(\mathrm{CE}>1)$ and low for subordinate species $(\mathrm{CE}<1)$, independent of the mixture type of interacting species groups (Fig. 4). In contrast, the inoculation of $G$. intraradices significantly modified
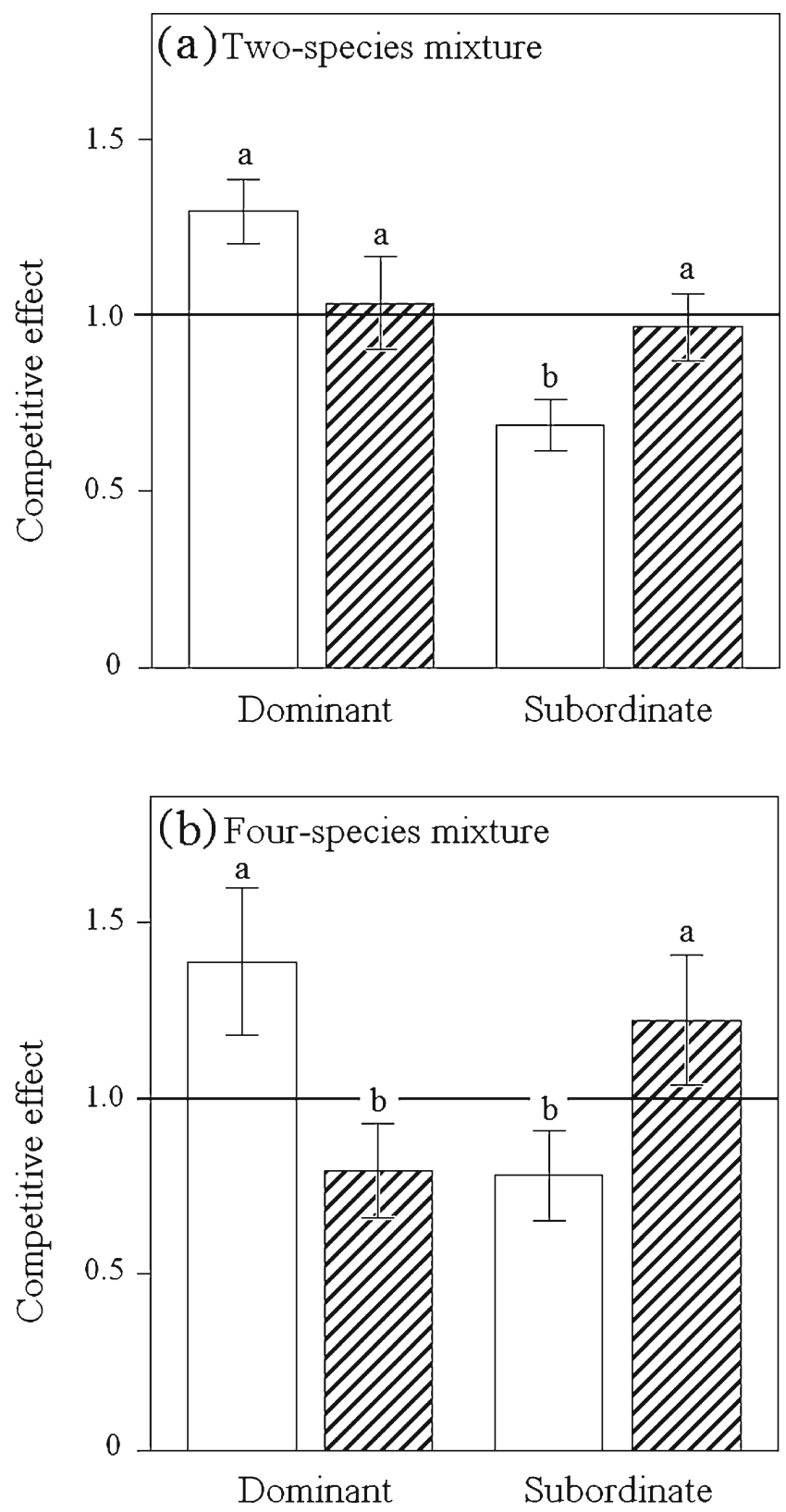

Fig. 4 Index of competitive effect $(\mathrm{CE} \pm 1 \mathrm{SE})$ of interacting dominant and subordinate species when grown in the presence (hatched bars) and absence (white bars) of the arbuscular mycorrhizal fungus $G$. intraradices in two-species mixture (a) and in four-species mixture (b). Horizontal lines indicate a CE value of 1 whereby species have equal competitiveness. Values above the line indicate a strongly competitive group, while values below the line indicate a weakly competitive group. Bars with different letters are significantly different $(P<$ $0.05)$ competitive effect of species groups (Table 1) with a decrease for dominants and an increase for subordinates in two- and four-species mixtures. In two-species mixtures comprising interacting species groups (Fig. 4a), both dominant and subordinate plants had a competitive effect close to 1 indicating that these two species groups had the same competitiveness in the presence of the AM fungus. In the four-species mixture comprising interacting species groups (Fig. 4b), the competitive effect of dominant species decreased $(\mathrm{CE}<1)$, whereas competitiveness of subordinates increased $(\mathrm{CE}>1)$, indicating that subordinates species were more competitive than dominant species.

\section{Discussion}

AM fungi affect plant growth and nutrition and thus have been shown to alter competitive relationships (Grime et al. 1987; Hartnett et al. 1993; Hartnett and Wilson 1999; Bever 2003; Scheublin et al. 2007). Whilst this was also the case in our study, the results demonstrated that plants colonised by $G$. intraradices performed worse (i.e. produced less biomass) than they did in the non-mycorrhizal conditions. These negative effects have also been observed on Triticum aestivum (Veiga et al. 2012), on Festuca ovina and Bromus erectus (Van der Heijden et al. 1998a, 2006) and Lolium multiflorum (Wagg et al. 2011) when colonised by the same fungal isolate (BEG 21), although such negative effects of mycorrhizal fungi on plant productivity are found only in $25 \%$ of published experiments (van der Heijden and Horton 2009). Thus, it appears that the plant/mycorrhizal system studied here was likely operating within the parasitic end of the mutualism-parasitism continuum highlighted by Johnson et al. (1997). This is also reflected by the large proportion of vesicles observed in the roots of all plant species (46-80\%). Vesicles are thought to be storage structures for carbon (Smith and Read 2008), and so the ratio between carbon allocation and mineral nutrient uptake might not be favourable from the perspective of the host (Johnson 2010). Indeed, changes in the relative abundance of vesicles in response to fertilisation have been shown previously to be indicative of mycorrhizal symbioses that reduce plant performance (Johnson 1993). Under the conditions of this experiment (low phosphorus and high light availability), we expected that the fungus acts as a mutualistic symbiont (Johnson et al. 1997), but this was not the case, and some other mechanisms may affect AM fungi activity in the mutualism-parasitism continuum. Indeed, only $G$. intraradices was manipulated in this experiment, and the absence of a diverse soil microbial community (i.e. soil competitors) may influence the direction of the symbiosis. Moreover, while the chemical characteristics were similar, the substrate used in pots (majority sand) was different from the field soil (clay loam). Soil texture may modify the impact of 
the symbiosis; and indeed, Zaller et al (2011) showed that different AM fungi can have greater effects on plant growth in soils with high sand content. However, these authors reported that the proportion of sand in the soil substrate does not affect the impact of the symbiosis and therefore would not explain the parasitic effects observed in our experiment.

Subordinate plant species were expected to be more dependent on AM fungi for growth than dominants (van der Heijden et al. 1998a; Karanika et al. 2008), and dominants were expected to grow equally well with or without AM fungi (Yao et al. 2007), but our results contradicted these expectations. G. intraradices had no effect on subordinate species and strongly detrimental effects on dominant species in the two- and four-species mixtures, whereas we observed a negative effect for all species in monoculture. The AM fungus influenced the growth of dominant and subordinate plants differently due to differential responses to G. intraradices in the mixtures. A. capillaris was the only grass in this experiment and was the plant most negatively affected by AM fungal inoculation. Grasses are known to be positively affected by AM fungal inoculation under mutualistic conditions (Wilson and Harnett 1998; Hoeksema et al. 2010) but, considering our results, grasses could also be more negatively affected by AM fungi in a less favourable AM relationship. Nevertheless, the other dominant species, the forb $T$. officinale, was also negatively affected by inoculation of G. intraradices in mixtures. The greatest AM fungal effect among species was observed in the four-species mixtures: P. vulgaris and A. millefolium (subordinates) were unaffected by the AM fungus, whereas A. capillaris and T. officinale (dominants) were negatively affected. Since subordinate species were negatively affected by the AM fungus in monoculture, these findings suggest that the neutrally mutualistic symbiosis between subordinates and $G$. intraradices may only occur in polyculture due to greater intensity of competition between each plant species. Indeed, no competitive hierarchy can be established in monoculture where only one plant species (subordinate or dominant) is available for the fungus. When plants grew in a mixture of subordinate and dominant species and a competitive hierarchy could be recognised, G. intraradices appeared to be selective among species groups in its intensity of parasitism, affecting more negatively the dominant species in the present experiment. We therefore suggest that AM fungi that potentially can supply larger amounts of mineral nutrients might select plant species with high biomass. Our results confirm the importance of neighbourhood identity and community composition that interacts with AM fungi to affect competitive outcomes of plants (Harnett et al. 1993; Collins and Foster 2009). In addition, competition theory postulates that for species coexistence, intraspecific competition should be stronger than interspecific competition (Amarasekare 2003), but our results showed that an AM fungus may modify the trend of this relationship. Indeed, in mycorrhizal pots, $P$. vulgaris suffered less and $A$. capillaris more from increasing interspecific competition by comparison to non-mycorrhizal pots. In contrast, the presence of $G$. intraradices did not change the trend of this relationship for A. millefolium or T. officinale. These findings highlight the key role of AM fungi in altering competitive relationships and suggest that theories on competition should include not only plant-plant interactions but also plant-soil associations to improve the understanding of species coexistence. However, as the effects of $G$. intraradices were plant species dependent in the present study, this reflects also the difficulties to conclude about clear patterns of AM fungal responsiveness.

Urcelay and Diaz (2003) hypothesised that interactions between subordinate and dominant plants are regulated by their increasingly positive growth responses to mycorrhizal fungi which ultimately shapes plant community composition and diversity. Based on this model, we hypothesised that AM fungi would flatten out differences in competitiveness among plant species because subordinates would have an advantage over dominants. Whilst data from the present experiment supported our hypothesis, in terms of reduction of competitiveness of dominant species, the mechanism was the opposite of what we predicted in that it was driven by differential responses of plant species to the parasitic effects of $G$. intraradices and an interaction with species mixture of the communities, rather than the positive effects of the fungus. The competitive effect of dominant species decreased in the presence of $G$. intraradices, whereas it increased for subordinate species independently of mixture type. In addition, the effect of the AM fungus on competitive effect was more intense in the mixture of four species than in the two-species mixture. Actually, in the two-species mixture, species groups became equally competitive $(\mathrm{CE}=$ 1) following a reduction in the differences in competitiveness between dominant and subordinates. In four-species mixture, an inversion of the competitive balance between species groups was observed with subordinates $(\mathrm{CE}>1)$ becoming more competitive than dominant species $(\mathrm{CE}<$ 1). In the present experiment, dominant species were clearly more competitive than subordinates in the absence of $G$. intraradices. In the presence of the fungus and depending on species composition, the competitive effect of dominant species decreased, leading to a reduced negative effect on subordinate species which enabled subordinates to be more competitive. Our findings highlight the role of mycorrhizas in allowing species coexistence by favouring less competitive species but also the importance of plant community type to mediate the effects of AM fungi.

The present findings provide new insight into the parasitic effects of AM fungi, which remain poorly studied, and give new perspectives for the model of Urcelay and Diaz (2003). Indeed, the results show that not only mutualism 
may influence dominance rankings, but that parasitism may also play a role when negative effects of AM fungi reduce the biomass and competitiveness of dominant species. According to these findings, we would predict dominant species to be less competitive in the presence of AM fungi and that this would flatten out the dominance hierarchy in communities, especially with increasing species richness, thus promoting species coexistence. Nevertheless, more studies are needed to improve our understanding of parasitism and the potential role of AM fungi for species diversity. It must be considered along gradients of soil $\mathrm{P}$ availability (Johnson 1993; Johnson et al. 1997) and plant density (Koide and Dickie 2002) which both may modify the responsiveness to AM fungi. Clearly, our predictions need to be supported by experiments with a greater number of fungi, plant species and culture conditions than used in the present study. Nonetheless, the present data provide the basis for undertaking such work, and they also highlight the potential importance of one species of AM fungi in shaping plant communities (Scheublin et al. 2007), although interactions among different AM fungi and plant species might generate really different outcomes in natural system (Klironomos 2003; van der Heijden et al. 2006; Wagg et al. 2011). It is likely that parasitic to strongly mutualistic responses to individual mycorrhizal fungi occur simultaneously in nature, and so understanding the conditions that lead to these contrasting responses and quantifying the net effect of mycorrhizal communities on ecosystems are important. Given the contrasting effects of plant species (Vandenkoornhuyse et al. 2003; Johnson et al. 2004; Hausmann and Hawkes 2009) on AM fungal community composition and functioning, belowground interactions may be a key process driving competition among neighbouring plants, and especially between dominant and subordinate species.

In conclusion, our findings point to the importance of plant composition to regulate the effects of AM fungi and to a potentially more negative effect on highly competitive species in mixtures when the fungus is functioning at the parasitic end of the mutualism-parasitism continuum. In natural plant communities, subordinate plants may therefore not only gain an advantage from associating with functionally mutualistic species of AM fungi (Urcelay and Diaz 2003) but may also be able to persist when the symbiosis is parasitic on dominant species, which may occur with changes in resource availability and/or AM fungal community structure. Thus, regardless of the overall benefit for plants of colonisation by AM fungi, asymmetry in the response of dominant and subordinate plants to mycorrhizal colonisation is likely to be a key process that regulates plant community structure in grassland.

Acknowledgments We thank Marcel van der Heijden and Charlotte Vandenberghe for their significant input in this project; PRIMPLANTS SA for the glasshouse accommodation; and Lionel Lobrutto, Grégory
Bernard, Claire Guenat, Géraldine Bullinger, Justine Mariotte, David Parietti, Didier Burkhalter, Jean-David Teuscher and Elena Rossel for technical assistance. This work was supported by the Swiss National Science Foundation (grant number 31003A-114139).

\section{References}

Amarasekare P (2003) Competitive coexistence in spatially structured environments: a synthesis. Ecol Lett 6:1109-1122

Baur B, Cremene C, Groza G, Rakosy L, Schileyko AA, Baur A, Stoll P, Erhardt A (2006) Effects of abandonment of subalpine hay meadows on plant and invertebrate diversity in Transylvania, Romania. Biol Conserv 132:261-273

Berns AE, Philipp H, Narres HD, Burauel P, Vereecken H, Tappe W (2008) Effect of gamma-sterilization and autoclaving on soil organic matter structure as studied by solid state NMR, UV and fluorescence spectroscopy. Eur J Soil Sci 59:540-550

Bever JD (2003) Soil community feedback and the coexistence of competitors: conceptual frameworks and empirical tests. New Phytol 157:465-473

Boeken B, Shachak M (2006) Linking community and ecosystem processes: the role of minor species. Ecosystems 9:119-127

Buttler A, Kohler F, Gillet F (2009) The Swiss mountain wooded pastures: patterns and processes. In: Rigueiro-Rodrigues A, et al (eds) Agroforestry in Europe, current status and future prospects. Advances in Agroforestry, vol. 6. Springer Science, p 450

Chen X, Tu C, Burton MG, Watson DM, Burkey KO, Hu S (2007) Plant nitrogen acquisition and interactions under elevated carbon dioxide: impact of endophytes and mycorrhizae. Global Change Biol 13:1238-1249

Collins CD, Foster BL (2009) Community-level consequences of mycorrhizae depend on phosphorus availability. Ecology 90:2567-2576

Cremene C, Groza G, Rakosy L, Schileyko AA, Baur A, Erhardt A, Baur B (2005) Alterations of steppe-like grasslands in Eastern Europe: a threat to regional biodiversity hotspots. Conserv Biol 19:1606-1618

Engel EC, Weltzin JF (2008) Can community composition be predicted from pairwise species interactions? Plant Ecol 195:77-85

Follett RF, Reed DA (2010) Soil carbon sequestration in grazing lands: societal benefits and policy implications. Rangeland Ecol Manag 63:4-15

Gavito ME, Schweiger P, Jakobsen I (2003) P uptake by arbuscular mycorrhizal hyphae: effect of soil temperature and atmospheric $\mathrm{CO}_{2}$ enrichment. Global Change Biol 9:106-116

Gerdemann JW (1955) Relation of a large soil-borne spore to phycomycetous mycorrhizal infections. Mycologia 47:619-632

Gigon A, Leutert A (1996) The dynamic keyhole-key model of coexistence to explain diversity of plants in limestone and other grasslands. J Veg Sci 7:29-40

Goldberg DE, Landa K (1991) Competitive effect and response: hierarchies and correlated traits in the early stages of competition. J Ecol 79:1013-1030

Grime JP (1998) Benefits of plant diversity to ecosystems: immediate, filter and founder effects. J Ecol 86:902-910

Grime JP, Mackey JML, Hillier SH, Read DJ (1987) Floristic diversity in a model system using experimental microcosms. Nature 328:420-422

Gross N, Le Bagousse-Pinguet Y, Liancourt P, Urcelay C, Catherine R, Lavorel S (2010) Trait-mediated effect of arbuscular mycorrhiza on the competitive effect and response of a monopolistic species. Funct Ecol 24:1122-1132

Hartnett DC, Wilson GWT (1999) Mycorrhizae influence plant community structure and diversity in tallgrass prairie. Ecology 80:11871195 
Hartnett DC, Hetrick BAD, Wilson GWT, Gibson DJ (1993) Mycorrhizal influence on intra- and interspecific neighbour interactions among co-occurring prairie grasses. J Ecol 81:787-795

Hausmann NT, Hawkes CV (2009) Plant neighborhood control of arbuscular mycorrhizal community composition. New Phytol 183:1188-1200

Hoeksema JD, Chaudhary VB, Gehring CA, Johnson NC, Karst J, Koide RT, Pringle A, Zabinski C, Bever JD, Moore JC, Wilson GWT, Klironomos JN, Umbanhowar J (2010) A meta-analysis of context-dependency in plant response to inoculation with mycorrhizal fungi. Ecol Lett 13:394-407

Johnson NC (1993) Can fertilization of soil select less mutualistic mycorrhizae? Ecol Appl 3:749-757

Johnson NC (2010) Resource stoichiometry elucidates the structure and function of arbuscular mycorrhizas across scales. New Phytol 185:631-647

Johnson NC, Graham J, Smith F (1997) Functioning of mycorrhizal associations along the mutualism-parasitism continuum. New Phytol 135:575-585

Johnson D, Leake JR, Read DJ (2001) Novel in-growth core system enables functional studies of grassland mycorrhizal mycelial networks. New Phytol 152:555-562

Johnson D, Leake JR, Ostle N, Ineson P, Read DJ (2002) In situ ${ }^{13} \mathrm{CO}_{2}$ pulse-labelling of upland grassland demonstrates a rapid pathway of carbon flux from arbuscular mycorrhizal mycelia to the soil. New Phytol 153:327-334

Johnson D, Vandenkoornhuyse PJ, Leake JR, Gilbert L, Booth RE, Grime JP, Young PW, Read DJ (2004) Plant communities affect arbuscular mycorrhizal fungal diversity and community composition in grassland microcosms. New Phytol 161:503-515

Karanika ED, Mamolos AP, Alifragis DA, Kalburthi KL, Veresoglou AD (2008) Arbuscular mycorrhizas contribution to nutrition, productivity, structure and diversity of plant community in mountainous herbaceous grassland of northern Greece. Plant Ecol 199:225-234

Klironomos JN (2003) Variation in plant response to native and exotic arbuscular mycorrhizal fungi. Ecology 84:2292-2301

Klironomos JN, Zobel M, Tibbett M, Stock WD, Rillig MC, Parrent JL, Moor M, Koch AM, Facelli JM, Facelli E, Dickie IA, Bever JD (2011) Forces that structure plant communities: quantifying the importance of mycorrhizal symbiosis. New Phytol 189:366-370

Koide RT, Dickie IA (2002) Effects of mycorrhizal fungi on plant populations. Plant Soil 244:307-317

Lyons KG, Brigham CA, Traut BH, Schwartz MW (2005) Rare species and ecosystem functioning. Conserv Biol 19:1019-1024

Mariotte P, Buttler A, Johnson D, Thébault A, Vandenberghe C (2012) Exclusion of root competition increases competitive abilities of subordinate plant species through root-shoot interactions. J Veg Sci. doi:10.1111/j.1654-1103.2012.01432.x

Olff H, Bakker JP (1998) Do intrinsically dominants species exist? A test statistic for field data. Appl Veg Sci 1:15-20

Öpik M, Moora M, Liira J, Zobel M (2006) Composition of rootcolonizing arbuscular mycorrhizal fungal communities in different ecosystems around the globe. J Ecol 96:778-790

R Development Core Team (2010) R: A Language and Environment for Statistical Computing. R Foundation for Statistical Computing, Vienna, Austria
Read DJ, Koucheki HK, Hodgson J (1976) Vesicular-arbuscular mycorrhiza in natural vegetation systems. New Phytol 77:641-653

Scheublin TR, van Logtestijn RSP, van der Heijden MGA (2007) Presence and identity of arbuscular mycorrhizal fungi influence competitive interactions between plant species. J Ecol 95:631-638

Smith SE, Read DJ (2008) Mycorrhizal symbioses, 3rd edn. Academic, London

Sýkorová Z, Wiemken A, Redecker D (2007) Cooccurring Gentiana verna and Gentiana acaulis and their neighboring plants in two Swiss upper montane meadows harbor distinct arbuscular mycorrhizal fungal communities. Appl Environ Microbiol 73:54265434

Urcelay C, Diaz S (2003) The mycorrhizal dependence of subordinates determines the effect of arbuscular mycorrhizal fungi on plant diversity. Ecol Lett 6:388-391

van der Heijden MGA, Horton TR (2009) Socialism in soil? The importance of mycorrhizal fungal networks for facilitation in natural ecosystems. J Ecol 97:1139-1150

van der Heijden MGA, Boller T, Wiemken A, Sanders IR (1998a) Different arbuscular mycorrhizal fungal species are potential determinants of plant community structure. Ecology 79:2082-2091

van der Heijden MGA, Klironomos JN, Ursic M, Moutoglis P, Steitwolf-Engel R, Boller T, Wiemken A, Sanders IR (1998b) Mycorrhizal fungal diversity determines plant biodiversity, ecosystem variability and productivity. Nature 396:69-72

van der Heijden MGA, Wiemken A, Sanders IR (2003) Different arbuscular mycorrhizal fungi alter coexistence and resource distribution between co-occurring plant. New Phytol 157:569-578

van der Heijden MGA, Scheublin TR, Brader A (2004) Taxonomic and functional diversity in arbuscular mycorrhizal fungi-is there any relationship? New Phytol 164:201-204

van der Heijden MGA, Streitwolf-Engel R, Riedl R, Siegrist S, Neudecker A, Ineichen K, Boller T, Wiemken A, Sanders IR (2006) The mycorrhizal contribution to plant productivity, plant nutrition and soil structure in experimental grassland. New Phytol 172:739-752

Vandenkoornhuyse P, Ridgeway KP, Watson IJ, Duck M, Fitter AH, Young JPW (2003) Co-existing grass species have distinctive arbuscular mycorrhizal communities. Mol Ecol 12:3085-3095

Veiga RSL, Howard K, van der Heijden MAG (2012) No evidence for allelopathic effects of arbuscular mycorrhizal fungi on the nonhost plant Stellaria media. Plant Soil. doi:10.1007/s11104-0121256-x

Wagg C, Jansa J, Schmid B, van der Heijden MGA (2011) Belowground biodiversity effects of plant symbionts support aboveground productivity. Ecol Lett 14:1001-1009

Whittaker RH (1965) Dominance and diversity in land plant communities. Science 147:250-260

Wilson GWT, Harnett DC (1998) Interspecific variation in plant responses to mycorrhizal colonization in tallgrass prairie. Am J Bot 85:1732-1738

Yao Q, Zhu HH, Hu YL, Li LQ (2007) Differential influence of native and introduced arbuscular mycorrhizal fungi on growth of dominant and subordinate plants. Plant Ecol 196:261-268

Zaller JG, Frank T, Drapela T (2011) Soil sand content can alter effects of different taxa of mycorrhizal fungi on plant biomass production of grassland species. Eur J Soil Biol 47:175-181 